\title{
Solvated Nickel Complexes as Stoichiometric and Catalytic Perfluoroalkylation Agents
}

Scott T. Shreiber and David A. Vicic*

Department of Chemistry, Lehigh University, 6 E. Packer Ave., Bethlehem, PA 18015

\begin{abstract}
The acetonitrile-solvated $\left[(\mathrm{MeCN}) \mathrm{Ni}\left(\mathrm{C}_{2} \mathrm{~F}_{5}\right)_{3}\right]^{-}$was prepared in order to compare and contrast its reactivity with the known $\left[(\mathrm{MeCN}) \mathrm{Ni}\left(\mathrm{CF}_{3}\right)_{3}\right]^{-}$towards organic electrophiles. Both $\left[(\mathrm{MeCN}) \mathrm{Ni}\left(\mathrm{CF}_{3}\right)_{3}\right]^{-}$ and $\left[(\mathrm{MeCN}) \mathrm{Ni}\left(\mathrm{C}_{2} \mathrm{~F}_{5}\right)_{3}\right]^{-}$successfully react with aryl iodonium and diazonium salts as well as alkynyl iodonium salts to give fluoroalkylated organic products. Electrochemical analysis of $\left[(\mathrm{MeCN}) \mathrm{Ni}^{\prime \prime}\left(\mathrm{C}_{2} \mathrm{~F}_{5}\right)_{3}\right]^{-}$ suggests that, upon electro-oxidation to $\left[(\mathrm{MeCN})_{n} \mathrm{Ni}^{i \prime \prime}\left(\mathrm{C}_{2} \mathrm{~F}_{5}\right)_{3}\right]$, reductive homolysis of a perfluoroethyl radical occurs, with the concomitant formation of $\left[(\mathrm{MeCN}) \mathrm{Ni}^{\prime \prime}\left(\mathrm{C}_{2} \mathrm{~F}_{5}\right)_{2}\right]$. Catalytic $\mathrm{C}-\mathrm{H}$ trifluoromethylations of electron rich arenes were successfully achieved using either $\left[(\mathrm{MeCN}) \mathrm{Ni}\left(\mathrm{CF}_{3}\right)_{3}\right]^{-}$ or the related $\left[\mathrm{Ni}_{(}\left(\mathrm{CF}_{3}\right)_{4}\right]^{2-}$. Stoichiometric reactions of the solvated nickel complexes reveal that "ligandless" nickel is exceptionally capable of serving as reservoir of $\mathrm{CF}_{3}$ anions or radicals under catalytically relevant conditions.
\end{abstract}

\section{Introduction}

Nickel is a promising platform for developing practical fluoroalkylation methodologies as fundamental steps relevant to chemical bond forming reactions have been established. Reductive eliminations involving fluoroalkyl groups have been demonstrated at higher valent states of nickel, ${ }^{1-4}$ the generation of fluoroalkyl radicals via electron transfer or atom abstraction reactions of fluoroalkyl electrophiles with nickel is known, ${ }^{5-12}$ fluoroalkyl-based transmetalating reagents readily react with nickel, ${ }^{13-15}$ and catalytic transformations involving select fluoroalkyl groups have been reported..$^{6,10-13,16-21}$ Nickel is also an earth-abundant metal with a reasonably low cost. However, most of the aforementioned chemical transformations involving fluoroalkyl groups required nickel to bear stabilizing ligands other than solvent. While in many cases ligands can serve to tune and enable the reactivity of a nickel center, in other cases they can prevent catalysis through redistributions that affect the speciation of an active form of the nickel catalyst. Moreover, extraneous non-solvento ligands raise the cost of a chemical process and can even contribute to the air-sensitivity of the system. Given these considerations, we became interested in developing new fluoroalkylation methods with nickel that employed solvent as the 
only coordinating ligand. Such reaction conditions have commonly been referred to as "ligandless" conditions in other systems. ${ }^{22-28}$

Previously, we found that $\left[\mathrm{PPh}_{4}\right] \mathbf{2}$ and $\left[\mathrm{PPh}_{4}\right]_{2} 3$ (Chart 1 ) could be synthesized by the addition of one and two equivalents of " $\mathrm{AgCF}_{3}$ " to $\mathbf{1}$ in the presence of $\left[\mathrm{PPh}_{4}\right] \mathrm{Cl}^{29}$ The electronic properties of $\mathbf{2}$ and $\mathbf{3}$ were extensively studied through the use of density functional theory (DFT) calculations, spectroscopyoriented configuration interaction (SORCI) calculations, X-ray absorption spectroscopy, and cyclic voltammetry. ${ }^{29}$ Interestingly, the data collectively show that $\mathbf{2}$ and $\mathbf{3}$ are better described as physically $d^{9}$ metal complexes with the additional hole delocalized over the multiple trifluoromethyl ligands. The "ligandless" complexes $\mathbf{2}$ and $\mathbf{3}$ also displayed preliminary reactivities that warranted follow-up investigations. For example, $\mathbf{2}$ was found to react with an aryl iodonium salt to yield trifluoromethylated arene, presumably through a high-valent, unsupported and formally nickel(IV) intermediate. Evidence that such architectures are accessible was provided by the synthesis and structural characterization of $\left[\mathrm{PPh}_{4}\right]_{2}\left[\mathrm{Ni}\left(\mathrm{CF}_{3}\right)_{4}\left(\mathrm{SO}_{4}\right)\right]\left(\mathbf{4}\right.$, Chart 1), the first example of a "ligandless" trifluoromethyl nickel(IV) complex. ${ }^{29}$ The high-valent complex 4, while it could be crystallized, was rather unstable in solution. The instability of high-valent solvento complexes was also evident in electrochemical experiments, where $\mathbf{2}$ and $\mathbf{3}$ displayed irreversible oxidations on the timescale of the cyclic voltammogram. We believed this redox instability could be beneficial in terms of catalysis, where high-valent intermediates would need to irreversibly form chemical bonds or release perfluoroalkyl radicals for chemistries that turn over. Therefore, we sought to investigate further the oxidative chemistries of $\mathbf{2}$ and $\mathbf{3}$ and compare the reactivities to those of a perfluoroethyl analogue.<smiles>CN(C)[N+](C)(C)C(F)(F)F</smiles>

1

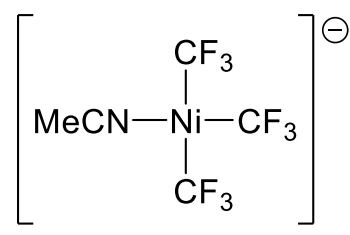

2

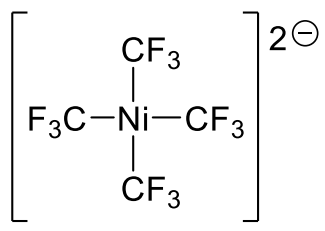

3

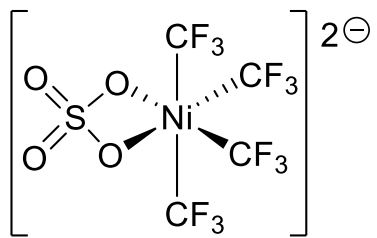

4

Chart 1. Trifluoromethyl nickel reagents previously characterized. 


\section{Results and Discussion}

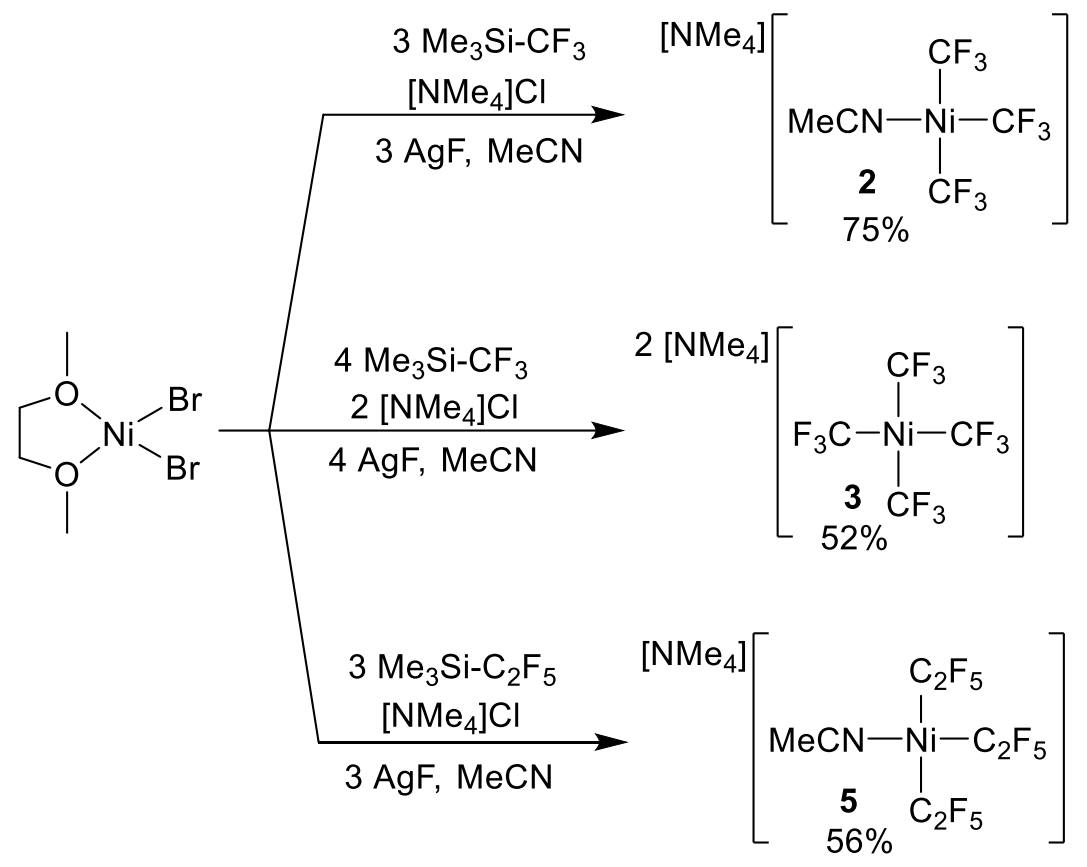

Scheme 1. Synthesis of tetramethylammonium salts of 2, 3, and 5.

We have shown previously that [PPh $]$ salts of $\mathbf{2}$ and $\mathbf{3}$ (Chart 1 ) were susceptible to side reactions involving organic nucleophiles and the phosphorus moiety, ${ }^{29}$ so herein we describe the preparation of tetramethylammonium salts of $\mathbf{2}, \mathbf{3}$, and the new perfluoroethyl derivative $\mathbf{5}$ (Scheme $\mathbf{1}$ ). Such compounds were easily prepared by the addition of "Ag- $\mathrm{R}_{\mathrm{f}}$ " to [(dme)NiBr$\left.r_{2}\right]$ in acetonitrile solvent in the presence of $\left[\mathrm{NMe}_{4}\right] \mathrm{Cl}$. The ${ }^{19} \mathrm{~F}$ NMR spectrum of $\mathbf{5}$ displays four signals with integrations consistent with two perfluoroethyl groups cis to the acetonitrile group and one perfluoroethyl group that is trans to the acetonitrile. The $\mathrm{CF}_{3}$ resonance that is trans to the coordinated acetonitrile appears as a quintet from the ${ }^{4} J_{\mathrm{FF}}$ coupling of the other two $\mathrm{CF}_{2}$ groups, while the resonance for the $\mathrm{CF}_{3}$ groups that are cis to the acetonitrile appear as a triplet. The absence of ${ }^{3} J_{\mathrm{FF}}$ coupling is common for perfluoroalkyl groups and is suggested to arise from the rotational averaging of coupling constants of opposite sign between the vicinal $\mathrm{CF}_{2}$ and $\mathrm{CF}_{3}$ groups. ${ }^{30-33}$ 


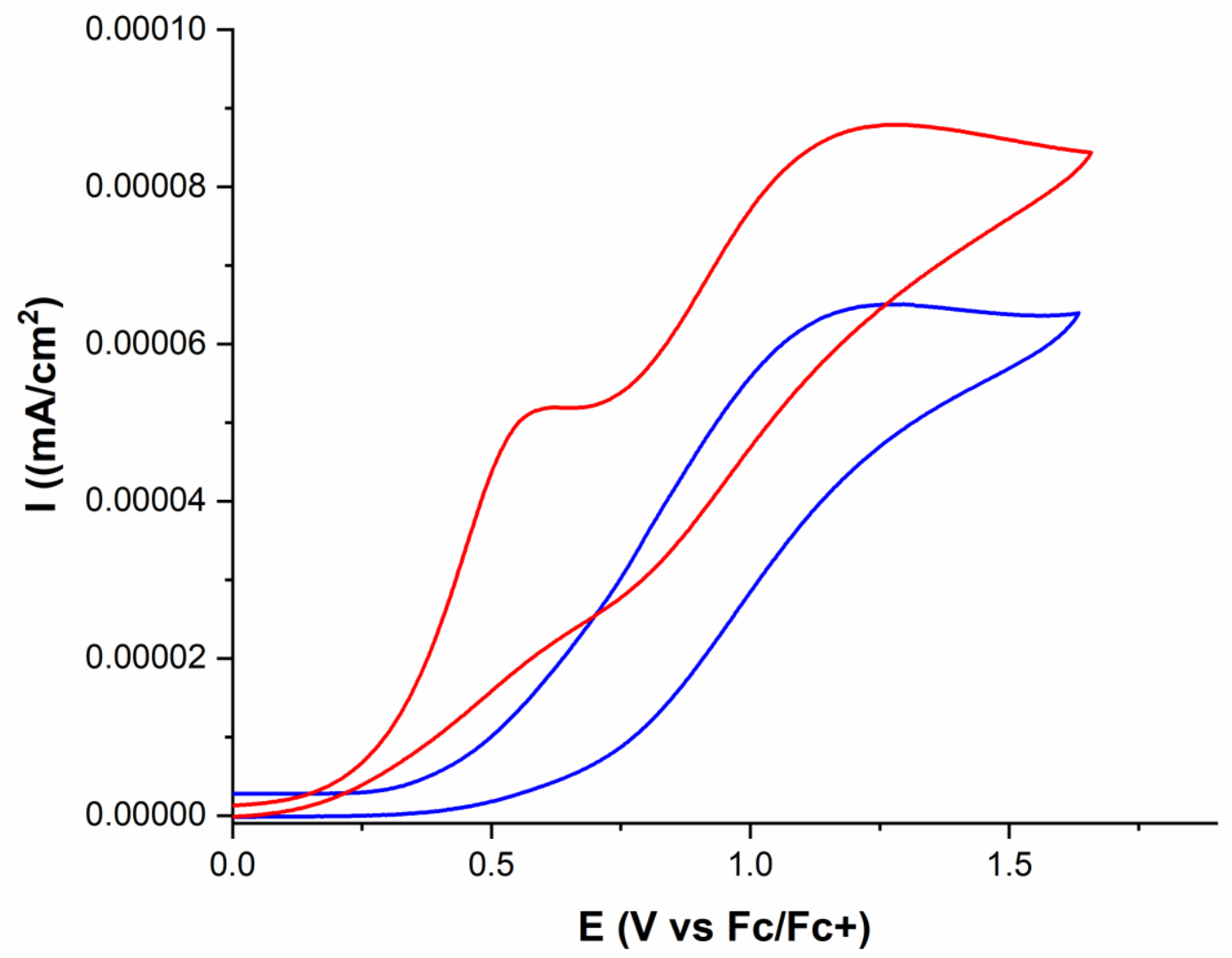

Figure 2. Cyclic voltammograms of $\left[(\mathrm{MeCN}) \mathrm{Ni}\left(\mathrm{C}_{2} \mathrm{~F}_{5}\right)_{3}\right]^{-}\left(5\right.$, red) and $\left[(\mathrm{MeCN})_{2} \mathrm{Ni}\left(\mathrm{C}_{2} \mathrm{~F}_{5}\right)_{2}\right](7$, blue) in $\mathrm{MeCN}$. Complex, $10 \mathrm{mM}$; electrolye, $100 \mathrm{mM}\left[\mathrm{NBu}_{4}\right]\left[\mathrm{PF}_{6}\right]$; working and counter electrode, platinum; silver psuedoreference; scan rate, $100 \mathrm{mV} / \mathrm{s}$.

The electrochemical properties of the newly prepared anionic complex $\mathbf{5}$ were evaluated by cyclic voltammetry (Figure 2). The oxidation of 5 is irreversible and occurs at an onset potential of $+0.21 \mathrm{~V}$ vs the ferrocene/ferrocenium couple. Peak potentials for $\mathbf{5}$ appear at $+0.60 \mathrm{~V}$ and $+1.26 \mathrm{~V}$, which are slightly more positive than peaks observed for the trifluoromethyl derivative $2 .^{29}$ Interestingly, the peak potential for the second redox event occurs at the same potential as the oxidation for the charge neutral bisperfluoroethyl complex 7 (Figure 2), consistent with the notion that upon oxidation to the nickel(III) species 6, a perfluoroethyl radical is lost which generates 7 during the timescale of the experiment (eq 1). Similar redox trends were found for the trifluoromethyl derivatives $\left[(\mathrm{MeCN}) \mathrm{Ni}\left(\mathrm{CF}_{3}\right)_{3}\right]^{-}(2)$ and $\left[(\mathrm{MeCN})_{2} \mathrm{Ni}\left(\mathrm{CF}_{3}\right)_{2}\right](\mathbf{1}),{ }^{29}$ suggesting that while the higher oxidation states of solvated nickel fluoroalkyl 
complexes can be easily accessed via oxidation of anionic complexes such as $\mathbf{2}$ and $\mathbf{5}$, the higher valent complexes have limited stabilities.

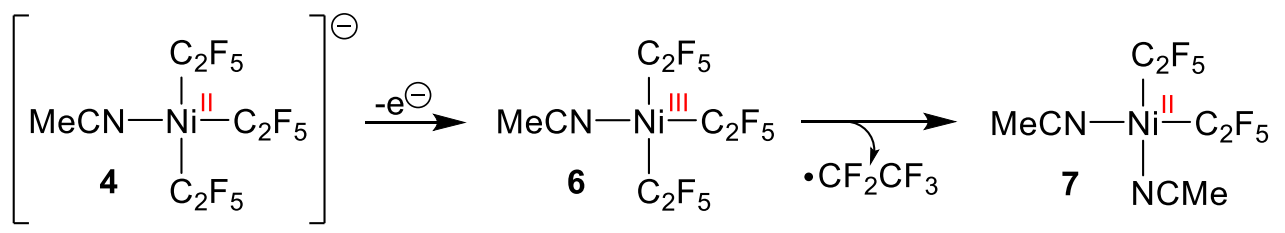

Given the accessible oxidations available to the solvated nickel fluoroalkyl complexes, we explored their reactivity with various oxidizing electrophiles. The reactivity of the tris-perfluoroalkyl nickelates with iodonium salts is summarized in Scheme 2. Quite different reactivities were observed depending on the iodonium salt used. Reaction with the alkynyl benziodoxolone reagent 8 (Scheme 2, eq 2) led to fluoroalkylated products ( $56 \%$ for $\mathrm{CF}_{3}$ and $54 \%$ for $\left.\mathrm{C}_{2} \mathrm{~F}_{5}\right)$. In the case of trifluoromethyl, $\left[(\mathrm{MeCN})_{2} \mathrm{Ni}\left(\mathrm{CF}_{3}\right)_{2}\right]$ was determined to be the major identifiable nickel species after reaction was complete. Reactions that occurred with bis(4-tert-butylphenyl)iodonium hexafluorophosphate are shown in Scheme 2, eq 3. Interestingly, even though more elevated temperatures were required, the byproducts $\left[(\mathrm{MeCN})_{2} \mathrm{Ni}\left(\mathrm{CF}_{3}\right)_{2}\right]$ and $\left[(\mathrm{MeCN})_{2} \mathrm{Ni}\left(\mathrm{C}_{2} \mathrm{~F}_{5}\right)_{2}\right]$ could be observed in higher quantities than the reactions described in eq 2 . 


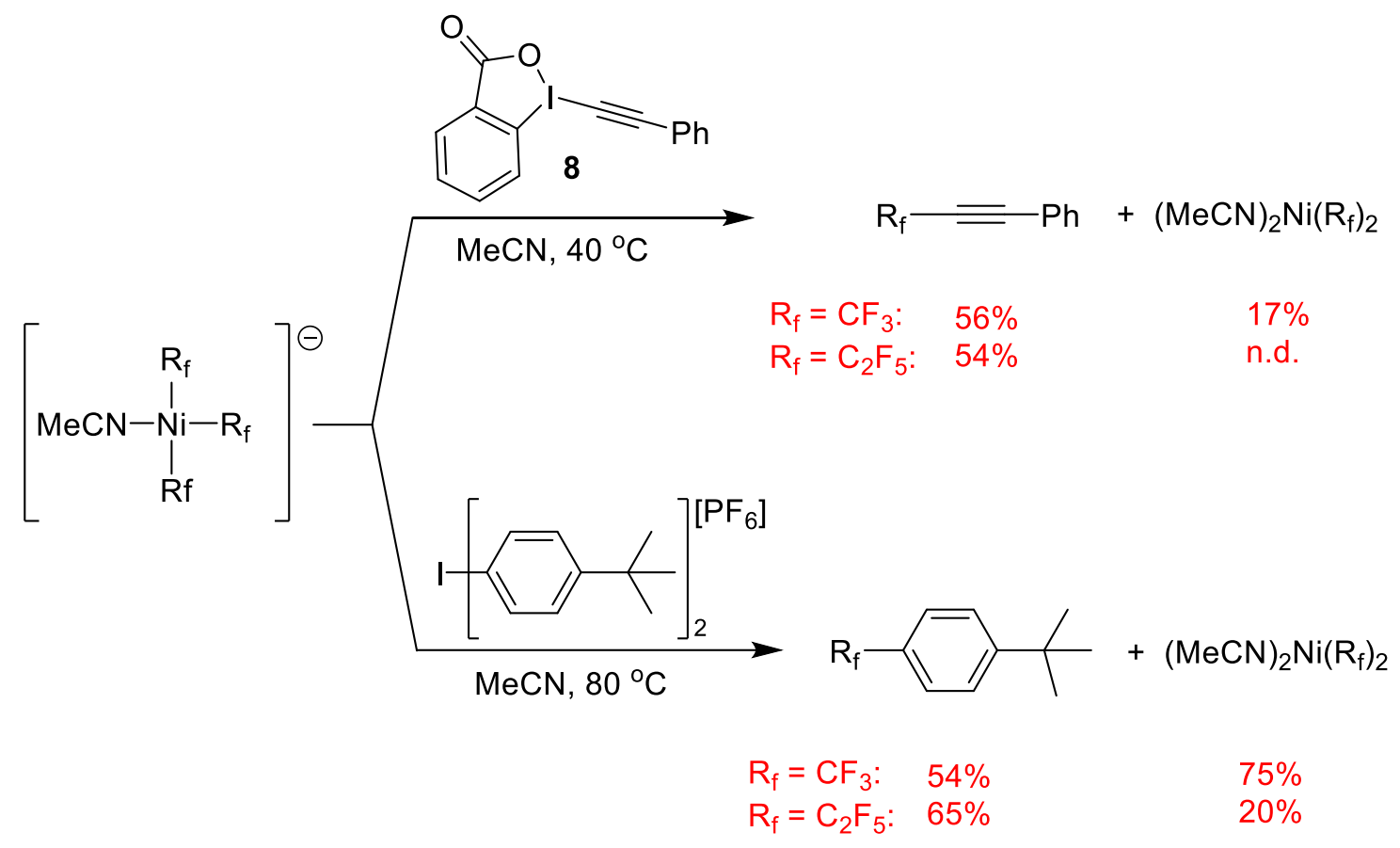

Scheme 2. Reaction of $\left[\mathrm{NMe}_{4}\right]\left[(\mathrm{MeCN}) \mathrm{Ni}\left(\mathrm{R}_{\mathrm{f}}\right)_{3}\right]$ with select iodonium salts. Yields determined by ${ }^{19} \mathrm{~F} N \mathrm{NMR}$ spectroscopy. See reference 29 for eq $3, \mathrm{R}_{\mathrm{f}}=\mathrm{CF}_{3}$.

Next, we explored reactions of the tris-perfluoroalkyl nickelates with diazonium salts, and the results are provided in Scheme 3. Reactions with the diazonium salts occurred more rapidly than the iodonium salts, and starting material was consumed after 15 minutes. Fluoroalkylated arenes were formed in fair to good yields (41-70\%), and similar reactivities were observed for both electron donating and withdrawing substituents (Scheme 3). Along with the fluorinated arenes, the bis(perfluoroalkyl)nickel byproducts were also observed in yields ranging from $30-62 \%$. Diazonium compounds, like iodonium salts, are known to act as two-electron oxidants, and it is plausible that, in both systems explored in Schemes 2 and 3, a high-valent species like $\left[\mathrm{Ar}-\mathrm{Ni}\left(\mathrm{R}_{\mathrm{f}}\right)_{3}(\mathrm{MeCN})_{2}\right]$ is involved in reductive eliminations that produces both fluoroalkylated arene and $\left[(\mathrm{MeCN})_{2} \mathrm{Ni}\left(\mathrm{R}_{\mathrm{f}}\right)_{2}\right]$ co-products. While we were unable to identify a charge-neutral and high valent $\left[\mathrm{Ar}-\mathrm{Ni}\left(\mathrm{R}_{\mathrm{f}}\right)_{3}(\mathrm{MeCN})_{2}\right]$ species, we show here that we can identify the related solvated species $\left[\mathrm{Ni}_{(}\left(\mathrm{CF}_{3}\right)_{4}(\mathrm{MeCN})_{2}\right]$ (9) upon chemical oxidation of $\left[\mathrm{Ni}_{(}\left(\mathrm{CF}_{3}\right)_{4}\right]^{2-}$. Reaction of $\left[\mathrm{Ni}\left(\mathrm{CF}_{3}\right)_{4}\right]^{2-}$ with two equivalents of Magic Blue oxidant led to 9 in $53 \%$ yield by ${ }^{19} \mathrm{~F}$ NMR spectroscopy (eq 4) and in $30 \%$ isolated yield. As there are two types of trifluoromethyl groups in complex $\mathbf{9}$ (trans to a $\mathrm{MeCN}$ and trans to another $\mathrm{CF}_{3}$ ), complex 9 exhibited two septets in the ${ }^{19} \mathrm{~F}$ NMR spectrum in acetonitrile $(\delta-19.2(J=7.2 \mathrm{~Hz})$ and $-30.7(\mathrm{sept}, J=7.2 \mathrm{~Hz})$. X-ray quality crystals could be grown from 
ether/pentane at low temperature, and an ORTEP diagram of 9 is shown in Figure 1. The trifluoromethyl groups that are trans to each other exhibit nickel-carbon distances of $2.0298(19) \AA$, while the trifluoromethyl groups that are trans to acetonitrile ligands were shorter at $1.9569(17) \AA$. This is consistent with the known trans influencing properties of the trifluoromethyl group. The nickel-carbon bond lengths of octahedral 9 in the formal +4 oxidation state were significantly longer than the average nickel(II)-carbon bond lengths in $\mathbf{3}(1.930(8) \AA ̊ ̊),{ }^{29}$ which adopts a distorted square planar arrangement in the formal +2 oxidation state and also possesses four trifluoromethyl ligands. To our knowledge, 9 represents only the second formally nickel(IV) complex reported bearing four trifluoromethyl ligands. ${ }^{29}$

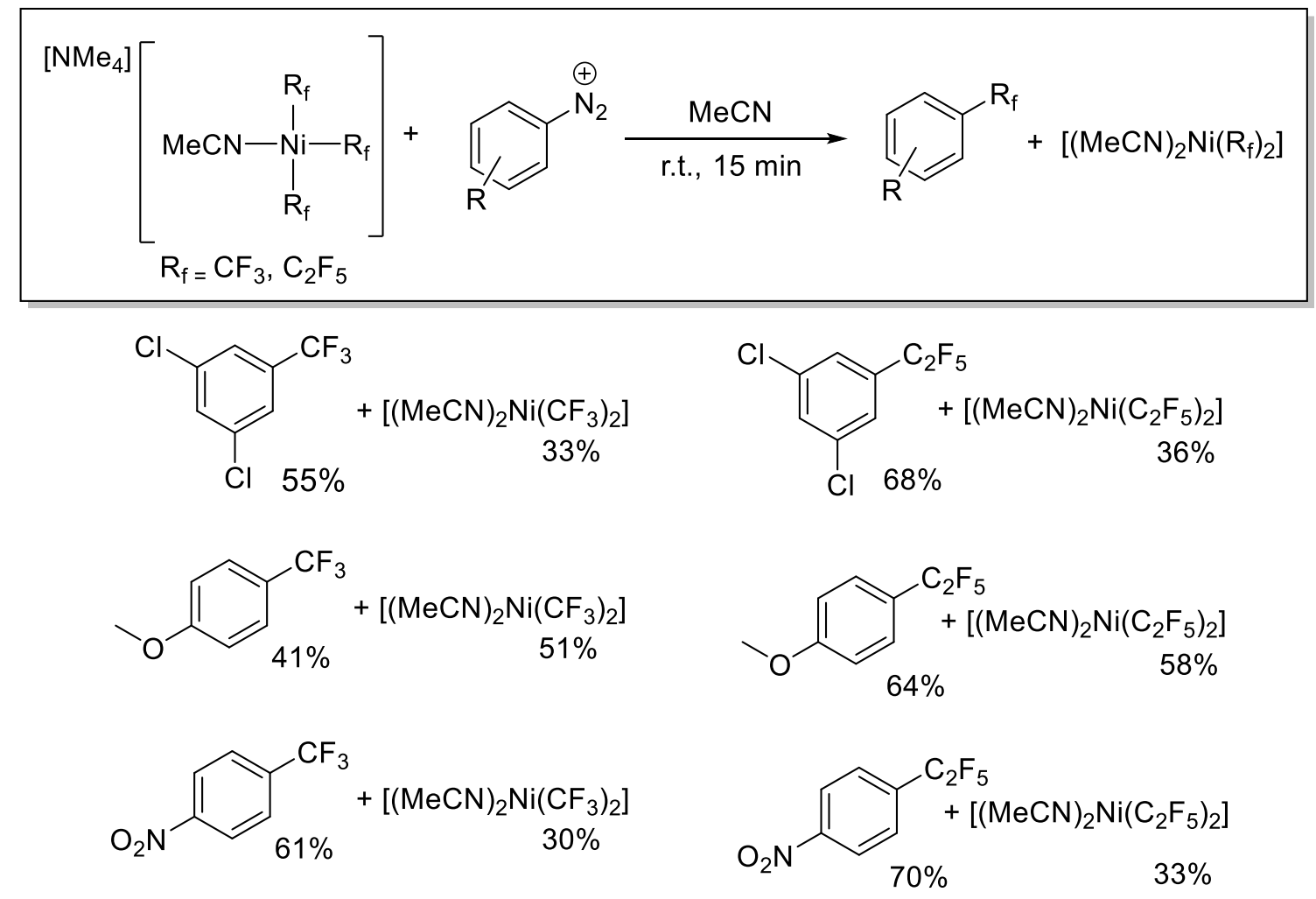

Scheme 3. Reaction of $\left[\mathrm{NMe}_{4}\right]\left[(\mathrm{MeCN}) \mathrm{Ni}\left(\mathrm{R}_{\mathrm{f}}\right)_{3}\right]$ with select diazonium salts. Yields were determined by ${ }^{19} \mathrm{~F}$ NMR spectroscopy relative to an internal standard. 


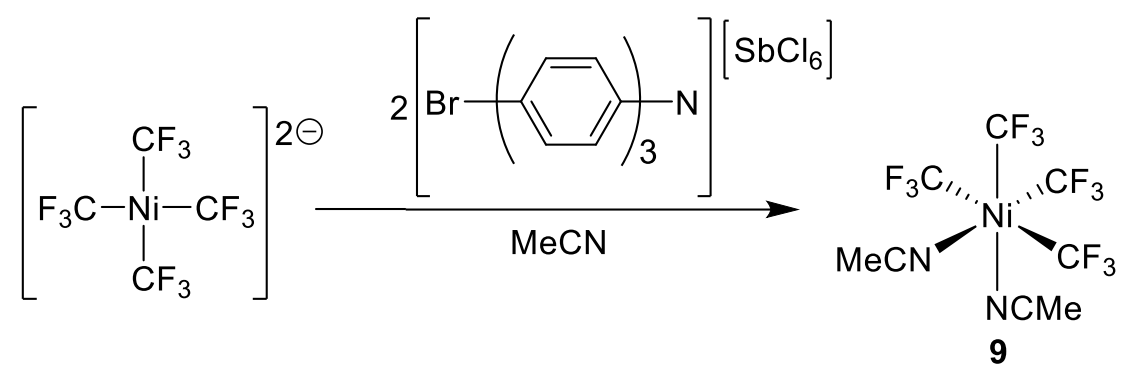

$53 \%$ NMR, $30 \%$ isolated

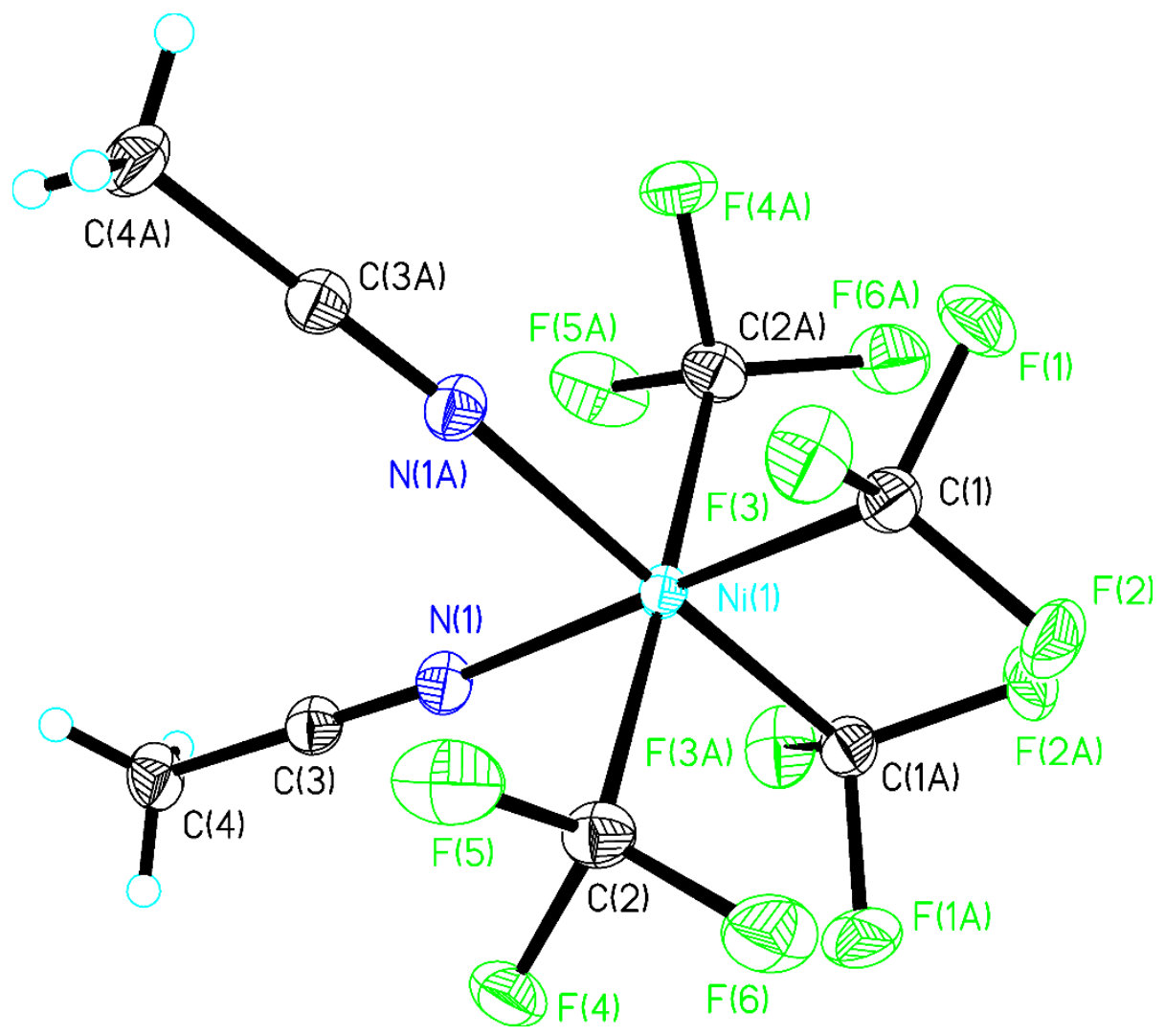

Figure 1. ORTEP diagram of 9. Ellipsoids shown at the $40 \%$ level. Selected bond lengths ( $\AA$ ): Ni1-C1 1.9569(17); Ni1-C2 2.0298(19); Ni1-N1 1.9682(15). Selected bond angles ( $\left.{ }^{\circ}\right)$ : C1-Ni1-N1 174.35(7); C1Ni1-N1A 91.62(7); N1-Ni1-N1A 85.54(8); C1-Ni1-C2 93.32(8); Ni-Ni1C2A 87.55(7). 
Because the cyclic volatmmograms of the anionic fluoroalkyl complexes of nickel revealed evidence of nickel-carbon bond homolyses reactions, we also examined the ability of solvated nickel complexes to perform Minisci-like C-H bond trifluoromethylations. In 2016, Wang reported the first example of a nickel-catalyzed $\mathrm{C}-\mathrm{H}$ trifluoromethylation of electron-rich heteroarenes using iodotrifluoromethane as the $\mathrm{CF}_{3}$ source and [(dppp) $\mathrm{NiCl}_{2}$ ] as the nickel source (dppp =1,3-bis(diphenylphosphino)propane). ${ }^{6}$ In

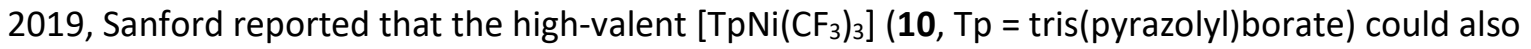
mediate catalytic $\mathrm{C}-\mathrm{H}$ trifluoromethylations of (hetero)arenes in the presence of Umemoto's Reagent II (11). ${ }^{17}$ Mechanistic investigations of this process, both experimental and computational, suggested that the reactions proceeded through radical chain pathways involving nickel in variable oxidation states. ${ }^{17}$ Since our "ligandless" nickel system could shuttle between the formally +2 to +4 oxidation states, we explored the possibility of using these complexes in similar $\mathrm{C}-\mathrm{H}$ trifluoromethylations, as eliminating the need for extraneous supporting ligands would represent a significant advance in practicality. Table 1 summarizes the catalyst screens for the $\mathrm{C}-\mathrm{H}$ trifluoromethylation reaction outlined in eq 5 that are based on the conditions identified by Sanford. Gratifyingly, the solvated complex $\mathbf{2}$ and the "ligandless" complex 3 catalyzed the trifluoromethylation of 1,3,5-trimethoxybenzene by Umemoto II reagent (eq 5) in 78 and 96\% yields, respectively, providing the first proof-in-principle that the solvated nickel complexes can perform catalytic trifluoromethylations. Notably, $\left[\mathrm{NMe}_{4}\right]_{2}\left[\mathrm{Ni}_{(}\left(\mathrm{CF}_{3}\right)_{4}\right](3)$ performed just as well as $\left[(\mathrm{Tp}) \mathrm{Ni}\left(\mathrm{CF}_{3}\right)_{3}\right](\mathbf{1 0})$ under these conditions, which was reported to afford product in $93 \%$ yield. ${ }^{17}$ To test the effect of metal identity on the $\mathrm{C}-\mathrm{H}$ trifluoromethylations, a reaction with the recently prepared $\left[(\mathrm{MeCN})_{3} \mathrm{Co}\left(\mathrm{CF}_{3}\right)_{3}\right](\mathbf{1 2})^{34}$ was examined (entry 5). Complex 12, while displaying catalytic turnover, afforded yields that were lower than nickel. With the optimal catalyst identified as $\left[\mathrm{NMe}_{4}\right]_{2}\left[\mathrm{Ni}\left(\mathrm{CF}_{3}\right)_{4}\right]$ in Table 1, we then determined the scope of the catalytic $\mathrm{C}-\mathrm{H}$ trifluoromethylations (Scheme 4). Trifluoromethylations of electron rich arenes $13 a-13 c$ proceeded smoothly, however introduction of an aldehyde into the aromatic scaffold (13d) lowered the yield of trifluoromethylated product significantly. Nitrogen- and sulfur-heterocycles (13e-13g) were also successfully trifluoromethylated. 
Table 1. Screening of fluoroalkyl transition metal catalysts for trifluoromethylation of arenes. ${ }^{a}$

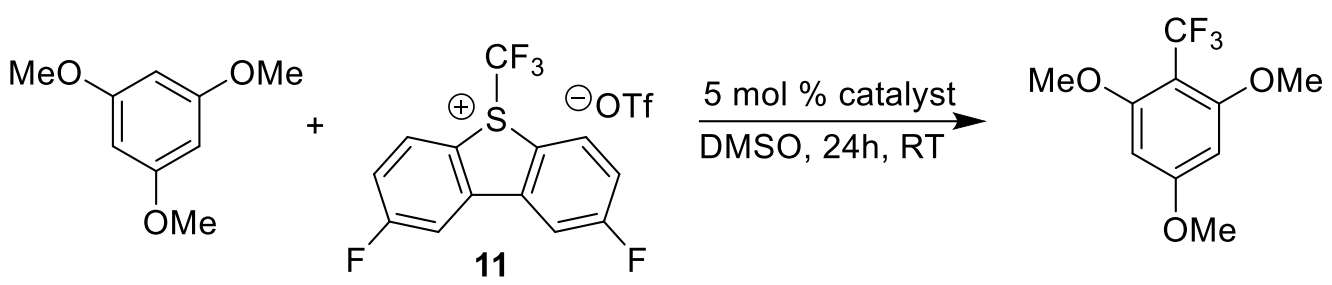

\begin{tabular}{|c|c|c|}
\hline entry & catalyst & yield \\
\hline 1 & {$\left[(\mathrm{Tp}) \mathrm{Ni}\left(\mathrm{CF}_{3}\right)_{3}\right](\mathbf{1 0})$} & $93^{17}$ \\
\hline 2 & none & 16 \\
\hline 3 & {$\left[\mathrm{NMe}_{4}\right]\left[(\mathrm{MeCN}) \mathrm{Ni}_{\left.\left(\mathrm{CF}_{3}\right)_{3}\right](\mathbf{2})}\right.$} & 78 \\
\hline 4 & $\left.\left[\mathrm{NMe}_{4}\right]_{2}\left[\mathrm{Ni}_{(\mathrm{CF}}\right)_{4}\right](\mathbf{3})$ & 96 \\
\hline 5 & {$\left[(\mathrm{MeCN})_{3} \mathrm{Co}\left(\mathrm{CF}_{3}\right)_{3}\right](\mathbf{1 2})$} & 59 \\
\hline
\end{tabular}

${ }^{a} A$ ll reactions were run on $0.05 \mathrm{mmol}$ scale with Umemoto Reagent II as the limiting reagent, and 5 equiv. of arene. The yields were determined by ${ }^{19} \mathrm{~F}$ NMR spectroscopy using trifluorotoluene as an internal standard. 


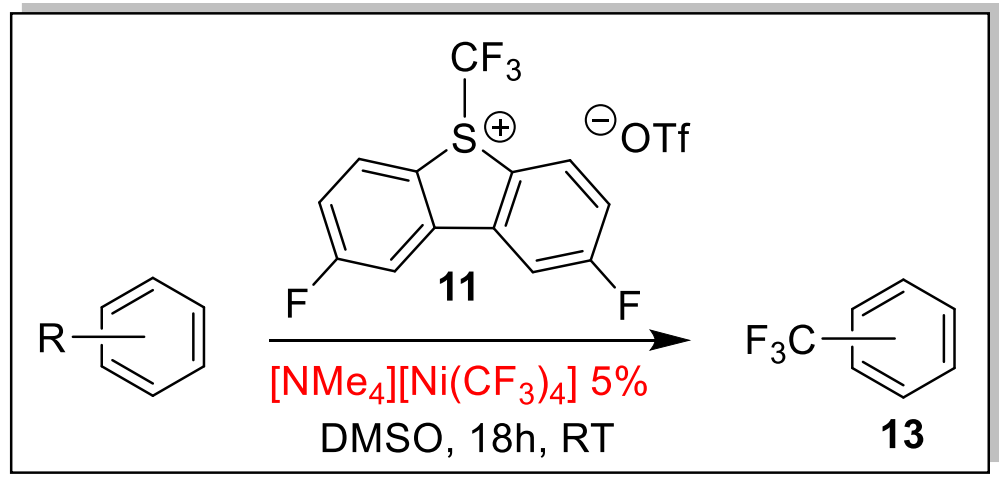<smiles>COc1cc(OC)cc(OC)c1</smiles>

13a $96 \%$<smiles>c1scc2c1OCCO2</smiles>
$13 \mathrm{e}$ $72 \%$<smiles>COc1cccc(OC)c1</smiles>

13b 91\%<smiles>[c]1[c]c2cccnc2[nH]1</smiles>

$13 f$ $51 \%$<smiles>Oc1ccccc1</smiles>

13c $99 \%$<smiles>COc1ccc2[nH]cc(CCP)c2c1</smiles><smiles>C=C(C)C</smiles>

13d

9\%

Scheme 4. Scope of catalytic $\mathrm{C}-\mathrm{H}$ functionalizations. The * reveals site(s) of selectivity for molecules with more than one type of aromatic $\mathrm{C}-\mathrm{H}$ bond. Combined yields of trifluoromethylations at all possible sites are provided. Yields were determined by ${ }^{19} \mathrm{~F}$ NMR spectroscopy relative to an internal standard.

To better understand the reactivity of $\left[\mathrm{NMe}_{4}\right]_{2}\left[\mathrm{Ni}_{(}\left(\mathrm{CF}_{3}\right)_{4}\right](\mathbf{3})$ with the Umemoto II reagent (11), a stoichiometric reaction was performed and monitored by ${ }^{19} \mathrm{~F}$ NMR spectroscopy. Upon mixing $\mathbf{3}$ with 11 in $\mathrm{CD}_{3} \mathrm{CN}$, the ${ }^{19} \mathrm{~F}$ NMR spectrum revealed a transformation that was consistent with the formation of compounds 14 and $\mathbf{1 5}$ (Scheme 5, eq 6). Putative compound 14 exhibits a singlet in the ${ }^{19} \mathrm{~F} \mathrm{NMR}$ spectrum in $\mathrm{CD}_{3} \mathrm{CN}$ at $\delta-25.1$. The ${ }^{19} \mathrm{~F}$ NMR spectrum of compound $\mathbf{1 5}$ is more complicated and consists of an apparent undecet at $\delta-19.6(J=8.2 \mathrm{~Hz})$ and a quartet at $\delta-28.8(J=8.2 \mathrm{~Hz})$. Compound 15 displays similarities in the ${ }^{19} \mathrm{~F}$ NMR spectrum to the $\mathrm{NCCH}_{2}-$ (carbon bound) complex $\left[\left(\mathrm{NCCH}_{2}\right) \mathrm{Ni}\left(\mathrm{CF}_{3}\right)_{5}\right]^{2-}$ (16), a compound that was formed in trace amounts during the synthesis $\mathbf{3}$, fortuitously crystallized, and was structurally characterized (see Supporting Information). The dianionic compound $\mathbf{1 6}$ displays resonances at $\delta-24.3$ (apparent septet, $J=7.5 \mathrm{~Hz}$ ) and -27.4 (quartet, $J=7.5 \mathrm{~Hz}$ ) in $\mathrm{CD}_{3} \mathrm{CN}$. In the absence of arene substrate (Scheme 5), we propose that $\mathbf{1 5}$ is formed via a sequential two electron 
oxidation of 3 by Umemoto II reagent as outlined in eqs 7 and 8. In catalytic reactions where arene trapping agents are present, $\mathrm{CF}_{3}$ radicals sources may originate both by the reaction described in eq 7 and by reductive homolysis of 17 , which would produce 2 as a byproduct. We speculate that the formation of $\mathbf{1 4}$ may arise through redistribution reactions involving trifluoromethyl anion (eq 9). The reactions described in eq 6-9 highlight the ability of solvated nickel to form trifluoromethyl complexes with a variety of coordination numbers, formal oxidation states, and formal overall charges. This flexible accommodation of trifluoromethyl groups may prove to be useful in future methodologies where nickel is required to serve as a reservoir of $\mathrm{CF}_{3}$ anions or radicals.

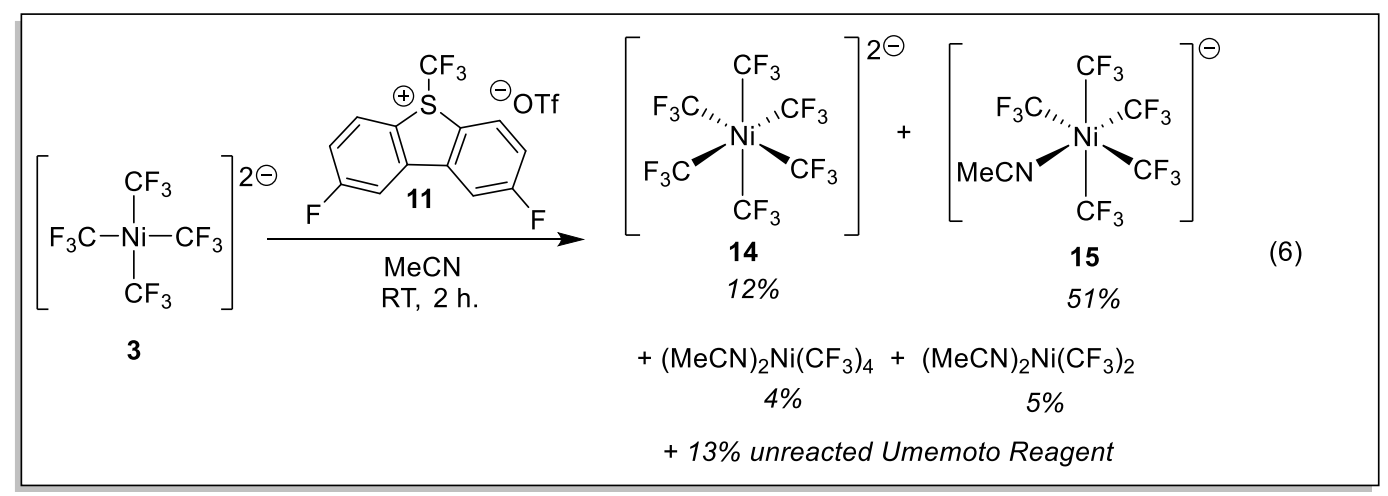

$\left[\begin{array}{c}\mathrm{CF}_{3} \\ \mathrm{~F}_{3} \mathrm{C}-\mathrm{Ni}-\mathrm{CF}_{3} \\ \mathrm{CF}_{3}\end{array}\right]^{2 \ominus}+$<smiles>Fc1ccc2c(c1)sc1ccc(F)cc12</smiles><smiles>Fc1ccc2c(c1)sc1ccc(F)cc12</smiles>

2,8-F,F-dibenzothiophene

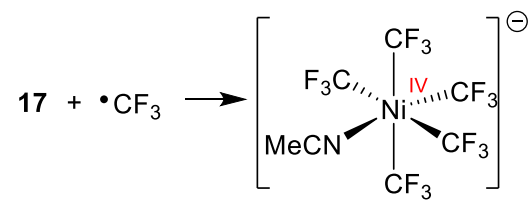

15

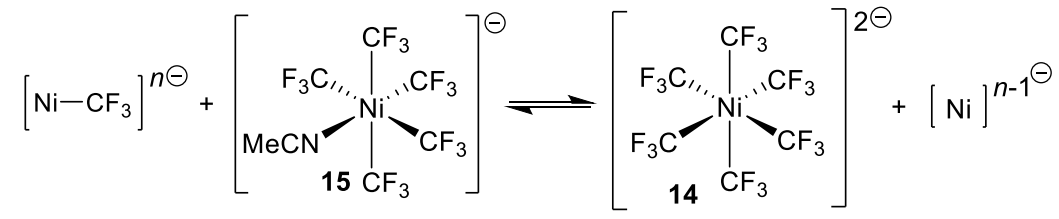

Scheme 5. Possible mechanistic pathways in the reaction of Umemoto II reagent with 3. 


\section{Conclusions}

A number of important precedents with regard to "ligandless" fluoroalkylations with nickel have been described. First, we show that both $\left[(\mathrm{MeCN}) \mathrm{Ni}\left(\mathrm{CF}_{3}\right)_{3}\right]^{-}$and $\left[(\mathrm{MeCN}) \mathrm{Ni}\left(\mathrm{C}_{2} \mathrm{~F}_{5}\right)_{3}\right]^{-}$successfully react with aryl iodonium and diazonium salts as well as alkynyl iodonium salts to give fluoroalkylated organic products. These results clearly show that upon oxidation of acetonitrile-supported nickel fluoroalkyl complexes, the fluoroalkyl groups can be transferred to organic substrates. Secondly, the electrochemical analysis of $\left[(\mathrm{MeCN}) \mathrm{Ni}^{\prime \prime}\left(\mathrm{C}_{2} \mathrm{~F}_{5}\right)_{3}\right]^{-}$suggests that, upon electro-oxidation to $\left[(\mathrm{MeCN})_{n} \mathrm{Ni}^{\prime \prime \prime}\left(\mathrm{C}_{2} \mathrm{~F}_{5}\right)_{3}\right]$, reductive homolysis of a perfluoroethyl radical occurs, with the concomitant formation of $\left[(\mathrm{MeCN}) \mathrm{Ni}^{\prime \prime}\left(\mathrm{C}_{2} \mathrm{~F}_{5}\right)_{2}\right]$. This electrochemical behavior shows generality with trifluoromethyl derivatives. ${ }^{29}$ Lastly, catalytic C-H trifluoromethylations of electron rich arenes were successfully achieved using either $\left[(\mathrm{MeCN}) \mathrm{Ni}\left(\mathrm{CF}_{3}\right)_{3}\right]^{-}$ or the related $\left[\mathrm{Ni}\left(\mathrm{CF}_{3}\right)_{4}\right]^{2-}$. Stoichiometric reactions of the solvated nickel complexes reveal that "ligandless" nickel is exceptionally capable of serving as reservoir of $\mathrm{CF}_{3}$ anions or radicals under catalytically relevant conditions, which bodes well for their use in future methods development.

\section{ASSOCIATED CONTENT}

Supporting Information Available: Crystallographic information files (CIF) and NMR spectral data. This material is available free of charge via the internet at http://pubs.acs.org.

\section{AUTHOR INFORMATION}

Corresponding author: *D. A. V.: fax, 1-610-758-6536. E-mail: vicic@lehigh.edu.

ORCID ID for David A. Vicic: 0000-0002-4990-0355

ORCID ID for Scott T. Shreiber: 0000-0002-4224-7461

Notes: The authors declare no competing financial interests

\section{ACKNOWLEDGEMENTS}

D.A.V. thanks the Office of Basic Energy Sciences of the U. S. Department of Energy (DE-SC0009363) for support of this work.

\section{Accession Codes}

CCDC 2074356 and 2074357 contain the supplementary crystallographic data for compounds 9 and 16, respectively. These data can be obtained free of charge via www.ccdc.cam.ac.uk/data_request/cif, or 
by e-mailing data_request@ccdc.cam.ac.uk, or by contacting The Cambridge Crystallographic Data Centre, 12 Union Road, Cambridge CB2 1EZ, UK; fax: +44 1223336033.

TOC Graphic:

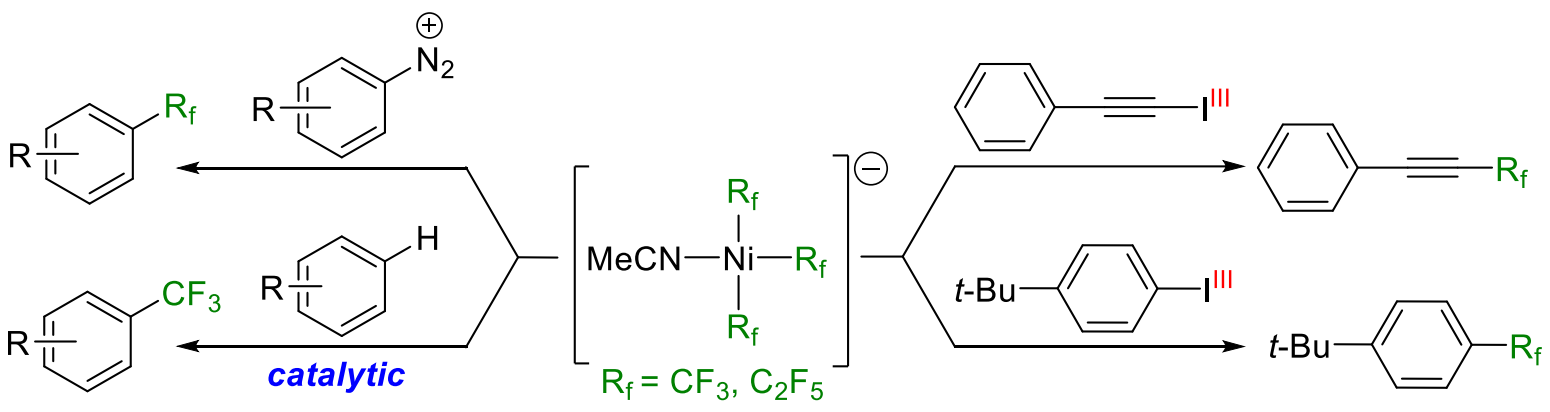




\section{References.}

1. Bour, J. R.; Camasso, N. M.; Sanford, M. S., Oxidation of Ni(II) to Ni(IV) with Aryl Electrophiles Enables Ni-Mediated Aryl-CF 3 Coupling. J. Am. Chem. Soc. 2015, 137, 8034-8037.

2. Bour, J. R.; Roy, P.; Canty, A. J.; Kampf, J. W.; Sanford, M. S., Oxidatively Induced Aryl-CF 3 Coupling at Diphosphine Nickel Complexes. Organometallics 2020, 39, 3-7.

3. Jongbloed, L. S.; Vogt, N.; Sandleben, A.; de Bruin, B.; Klein, A.; van der Vlugt, J. I., Nickel-Alkyl Complexes with a Reactive PNC-Pincer Ligand. Eur. J. Inorg. Chem. 2018, 2408-2418.

4. Bour, J. R.; Camasso, N. M.; Meucci, E. A.; Kampf, J. W.; Canty, A. J.; Sanford, M. S., CarbonCarbon Bond-Forming Reductive Elimination from Isolated Nickel(III) Complexes. J. Amer. Chem. Soc. 2016, 138, 16105-16111.

5. Mikhaylov, D. Y.; Budnikova, Y. H.; Gryaznova, T. V.; Krivolapov, D. V.; Litvinov, I. A.; Vicic, D. A.; Sinyashin, O. G., Electrocatalytic fluoroalkylation of olefins. J. Organomet. Chem. 2009, 694, 3840-3843.

6. Wu, Y.; Zhang, H.-R.; Jin, R.-X.; Lan, Q.; Wang, X.-S., Nickel-Catalyzed C-H Trifluoromethylation of Electron-Rich Heteroarenes. Adv. Syn. Cat. 2016, 358, 3528-3533.

7. Xu, C.; Cheng, R.; Luo, Y.-C.; Wang, M.-K.; Zhang, X., trans-Selective Aryldifluoroalkylation of Endocyclic Enecarbamates and Enamides by Nickel Catalysis. Angew. Chem., Int. Ed. 2020, 59, 18741-18747.

8. Fu, X.-P.; Xiao, Y.-L.; Zhang, X., Nickel-Catalyzed Difluoromethylation of Arylboronic Acids with Bromodifluoromethane. Chinese J. Chem. 2018, 36, 143-146.

9. Gao Xing, H. X. Z. X., Nickel-Catalyzed Difluoromethylation of (Hetero)aryl Bromides with $\mathrm{BrCF}_{2} \mathrm{H}$. Chinese J. Org. Chem. 2019, 39, 215-222.

10. Zhang, S.; Weniger, F.; Ye, F.; Rabeah, J.; Ellinger, S.; Zaragoza, F.; Taeschler, C.; Neumann, H.; Brueckner, A.; Beller, M., Selective nickel-catalyzed fluoroalkylations of olefins. Chem. Commun. 2020, 56, 15157-15160.

11. Xu, C.; Guo, W.-H.; He, X.; Guo, Y.-L.; Zhang, X.-Y.; Zhang, X., Difluoromethylation of (hetero)aryl chlorides with chlorodifluoromethane catalyzed by nickel. Nat. Commun. 2018, 9, 110.

12. An, L.; Xu, C.; Zhang, X., Highly selective nickel-catalyzed gem-difluoropropargylation of unactivated alkylzinc reagents. Nat. Commun. 2017, 8, 1460.

13. Xu, L.; Vicic, D. A., Direct Difluoromethylation of Aryl Halides via Base Metal Catalysis at Room Temperature. J. Amer. Chem. Soc. 2016, 138, 2536-2539.

14. Kaplan, P. T.; Xu, L.; Chen, B.; McGarry, K. R.; Yu, S.; Wang, H.; Vicic, D. A., Mild, Safe, and Versatile Reagents for $\left(\mathrm{CF}_{2}\right)_{n}$ Transfer and the Construction of Fluoroalkyl-Containing Rings. Organometallics 2013, 32, 7552-7558.

15. Zhang, C.-P.; Wang, H.; Klein, A.; Biewer, C.; Stirnat, K.; Yamaguchi, Y.; Xu, L.; Gomez-Benitez, V.; Vicic, D. A., A Five-Coordinate Nickel(II) Fluoroalkyl Complex as a Precursor to a Spectroscopically Detectable Ni(III) Species. J. Am. Chem. Soc. 2013, 135, 8141-8144.

16. Feng, Z.; Xiao, Y.-L.; Zhang, X., Transition-Metal (Cu, Pd, Ni)-Catalyzed Difluoroalkylation via Cross-Coupling with Difluoroalkyl Halides. Acc. Chem. Res. 2018, 51, 2264-2278.

17. Meucci, E. A.; Nguyen, S. N.; Camasso, N. M.; Chong, E.; Ariafard, A.; Canty, A. J.; Sanford, M. S., Nickel(IV)-Catalyzed C-H Trifluoromethylation of (Hetero)arenes. J. Am. Chem. Soc. 2019, 141, 12872-12879.

18. Zhou, M.; Zhao, H.-Y.; Zhang, S.; Zhang, Y.; Zhang, X., Nickel-Catalyzed Four-Component Carbocarbonylation of Alkenes under 1 atm of CO. J. Am. Chem. Soc. 2020, 142, 18191-18199.

19. Zhao, H.-Y.; Gao, X.; Zhang, S.; Zhang, X., Nickel-Catalyzed Carbonylation of Difluoroalkyl Bromides with Arylboronic Acids. Org. Lett. 2019, 21, 1031-1036. 
20. Mikhaylov, D. Y.; Budnikova, Y. H.; Gryaznova, T. V.; Sinyashin, O. G., Electrocatalytic fluoroalkylation of olefins. ECS Trans. 2010, 25, 67-77.

21. An, L.; Tong, F.-F.; Zhang, S.; Zhang, X., Stereoselective Functionalization of Racemic Cyclopropylzinc Reagents via Enantiodivergent Relay Coupling. J. Am. Chem. Soc. 2020, 142, 11884-11892.

22. Carrow, B. P.; Hartwig, J. F., Ligandless, Anionic, Arylpalladium Halide Intermediates in the Heck Reaction. J. Amer. Chem. Soc. 2010, 132, 79-81.

23. Fantasia, S.; Windisch, J.; Scalone, M., Ligandless Copper-Catalyzed Coupling of Heteroaryl Bromides with Gaseous Ammonia. Adv. Syn. Cat. 2013, 355, 627-631.

24. Schroeter, F.; Lerch, S.; Strassner, T., Oxidative and Reductive Cross-Coupling Reactions Catalyzed by an Anionic "Ligandless" Palladium Complex. Org. Process Res. Dev. 2018, 22, 16141621.

25. Williams, D. R.; Bawel, S. A., General Methodology for the Preparation of Unsymmetrical $\alpha$ Linked Bisenones via Ligandless Cross-Coupling Reactions. Org. Lett. 2017, 19, 1730-1733.

26. Yin, J. X.; Hyland, C. J. T., Ring-Opening of Vinylcyclopropane-1,1-dicarboxylates by Boronic Acids under Ligandless Palladium Catalysis in Neat Water. J. Org. Chem. 2015, 80, 6529-6536.

27. Wiskur, S. L.; Korte, A.; Fu, G. C., Cross-couplings of alkyl electrophiles under "ligandless" conditions: Negishi reactions of organozirconium reagents. J. Am. Chem. Soc. 2004, 126, 82-83.

28. Madin, A.; Overman, L. E., Controlling stereoselection in intramolecular Heck reactions by tailoring the palladium catalyst. Tet. Lett. 1992, 33, 4859-62.

29. Shreiber, S. T.; DiMucci, I. M.; Khrizanforov, M. N.; Titus, C. J.; Nordlund, D.; Dudkina, Y.; Cramer, R. E.; Budnikova, Y.; Lancaster, K. M.; Vicic, D. A., [(MeCN)Ni( $\left.\left(\mathrm{CF}_{3}\right)_{3}\right]^{-}$and $\left[\mathrm{Ni}\left(\mathrm{CF}_{3}\right)_{4}\right]^{2-}$ : Foundations toward the Development of Trifluoromethylations at Unsupported Nickel. Inorg. Chem. 2020, 59, 9143-9151.

30. Graves, R. E.; Newmark, R. A., Fluorine coupling in hexalfuoroethane. J. Chem. Phys. 1967, 47, 3681-2.

31. Newmark, R. A., Vicinal fluorine-fluorine coupling constants in perfluoropropyl groups. J. Fluorine Chem. 2009, 130, 389-393.

32. Harris, R. K.; Woodman, C. M., N.M.R. spectra of molecules containing CF2 groups. II. Perfluorobutane. J. Mol. Spectrosc. 1968, 26, 432-43.

33. Shreiber, S. T.; Scudder, J. J.; Vicic, D. A., [(MeCN $\left.)_{3} \mathrm{Co}\left(\mathrm{C}_{2} \mathrm{~F}_{5}\right)_{3}\right]$ : A Versatile Precursor to Cobalt(III) Perfluoroethyl Complexes. Organometallics 2019, 38, 3169-3173.

34. Xue, T.; Vicic, D. A., Routes to Acetonitrile-Supported Trifluoromethyl and Perfluorometallacyclopentane Complexes of Cobalt. Organometallics 2020, 39, 3715-3720. 